\title{
Variation in the population biology of stripey bass Lutjanus carponotatus within and between two island groups on the Great Barrier Reef
}

\author{
Jacob P. Kritzer* \\ School of Marine Biology \& Aquaculture and CRC Reef Research Centre, James Cook University, Townsville, \\ Queensland 4810, Australia
}

\begin{abstract}
Density, population structure, mortality and growth of Lutjanus carponotatus on the Great Barrier Reef were compared on 2 spatial scales: between the Lizard and Palm Island groups and among 4 locations within the Palm group. The mean density at the Palm group was approximately 7 times that of the Lizard group. There were 2-fold differences in density within the Palm group, but strong statistical signals were not detected due to high variability in the data. Differences in size structures and asymptotic body sizes between the island groups were pronounced, and smaller differences were also evident within the Palm group. While age structures were similar among Palm group locations and lacked anomalous peaks, a series of strong cohorts at older age classes at the Lizard group suggests greater recruitment variability there during the past 2 decades. Variability in mortality did not increase with scale, as larger differences existed within the Palm group than between it and the Lizard group. The population traits estimated in this study were used in conjunction with reef area data to generate estimates of abundance and biomass, the values of which illustrate how multiple population traits interact to ultimately determine population size and reproductive potential. Multi-scale studies that examine a variety of aspects of population biology are rare for large reef fish, but are needed to identify which traits are likely to exhibit variation on which spatial scales.
\end{abstract}

KEY WORDS: Coral reef fish $\cdot$ Demography $\cdot$ Spatial variation $\cdot$ Growth $\cdot$ Mortality Resale or republication not permitted without written consent of the publisher

\section{INTRODUCTION}

The dynamics of ecological systems are driven by processes that operate on a variety of spatial scales. The identification and integration of these scales has been called the 'central problem in ecology' (Levin 1992, p. 1943). Coral reef fish ecologists have been criticized for working at scales that are too small relative to the systems in which their focal species live, but broad understanding of spatial patterns will require compiling data sets for a variety of species on a variety of scales (Choat 1998). Many reef fish species spend

${ }^{*}$ Present address: Department of Biological Sciences, University of Windsor, Windsor, Ontario N9B 3P4, Canada.

Email: kritzer@uwindsor.ca much of their lives in areas covering only a few meters, and studies working at these scales are not only appropriate but are necessary complements to larger-scale studies such as those investigating larval dispersal (Sale 1998). As principles of reef fish ecology, established largely through work on small-bodied taxa, begin to be explored with respect to larger and more mobile taxa, the minimum spatial scales must increase. For larger species that move over larger areas, comparisons among inter-mixed benthic populations might require individual reefs to be the minimum spatial scale at which individuals share overlapping home ranges, resources and habitat. Even individual reefs might not be appropriate as a minimum spatial unit if the focal question involves comparisons of patterns in recruitment, which can be correlated at large spatial scales for marine fishes (Myers et al. 1997; but see 
Doherty 1987). When possible, multi-scale studies will be preferable as they provide more informative insights into the generality of and variability in patterns and processes (Sale 1998).

In addition to a multi-scale perspective, attention to aspects of population biology beyond measures of abundance can enable more comprehensive understanding of population dynamics (Jones 1991). This has long been recognized in single-species reef fish studies, which often investigate demographic processes and aspects of population structure along with the abundance measures that typify community-level studies (Robertson 1998). However, the majority of single-species studies examining spatial patterns in population structure and demographic processes have worked with small, site-attached species (e.g. Pitcher 1992, Doherty \& Fowler 1994, Meekan et al. 2001). In contrast, research on larger predators that are often the targets of coral reef fisheries typically report population parameters averaged across many locations, or at best make spatial comparisons on very broad scales (100s of km or more; Newman et al. 1996). The relevance of ideas about how reef fish populations are structured, ideas that have been generated primarily by work on smaller species, can best be assessed for large reef fishes by increased attention to population traits of these taxa (Roberts 1996) on multiple spatial scales.

The present study examined population biology of the stripey bass Lutjanus carponotatus, a mid-sized snapper (maximum reported length of $40 \mathrm{~cm}$; Randall et al. 1997) which is part of a complex of shallow-water lutjanids that are common predators on coral reefs of the Great Barrier Reef (GBR) system, as well as other regions of the Indo-west Pacific. Density, size structure, age structure, mortality and growth of $L$. carponotatus were compared among 4 locations within the Palm Island group on the central GBR. These same traits were also compared between the Palm Island group locations and the Lizard Island group on the northern GBR as a single location. Population densities were further compared among sites within each location and among reef zones within sites. Additionally, these data were used in conjunction with estimates of reef area to estimate abundance and biomass at each location in order to illustrate the combined effects of multiple aspects of population biology in determining overall population size and, therefore, reproductive potential as well.

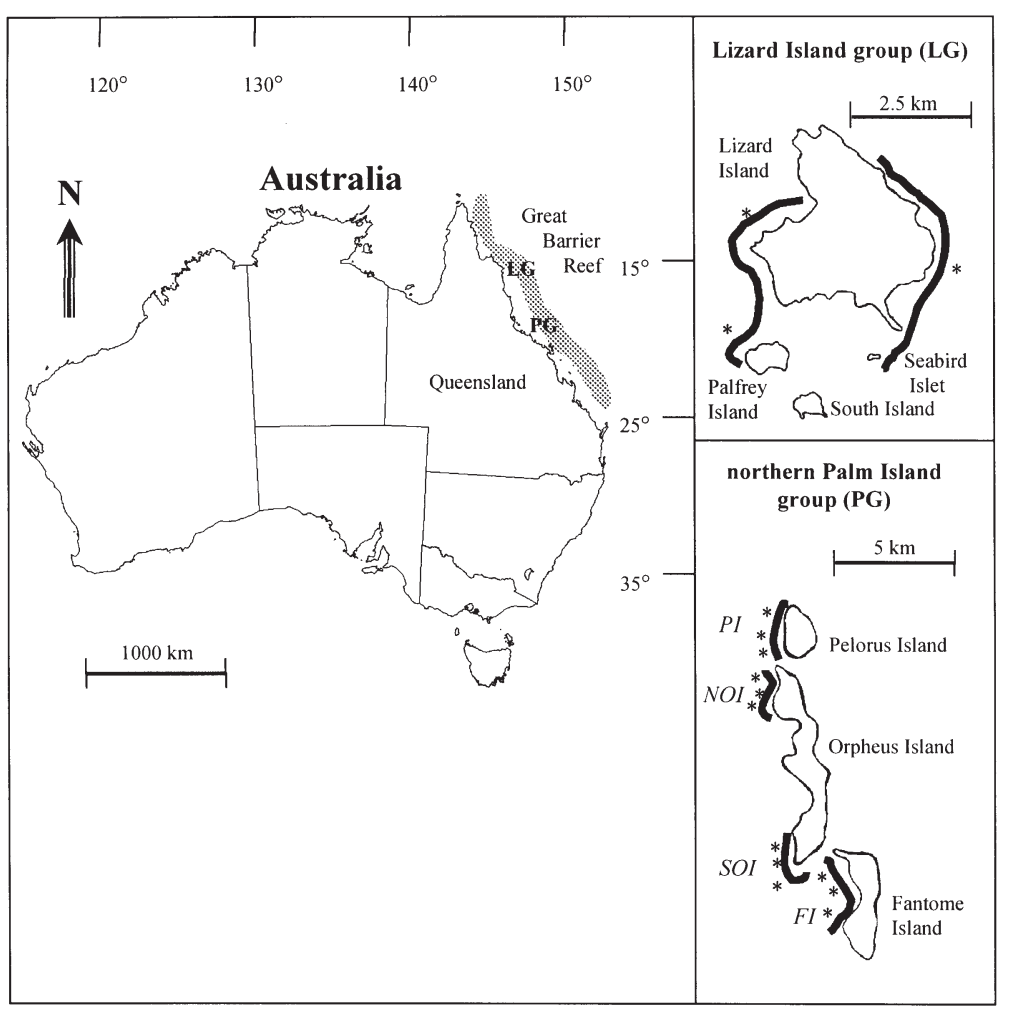

Fig. 1. Study locations within the Palm and Lizard Island groups. The Lizard Island group as a whole is treated as one location. Locations within the Palm Island group are Pelorus Is. (PI), northern Orpheus Is. (NOI), southern Orpheus Is. (SOI) and Fantome Is. (FI). Thick lines trace areas from which samples were collected; $*$ : census sites

\section{MATERIALS AND METHODS}

Study locations and spatial scales. In the Palm Island group, 4 locations were sampled: Pelorus Island, northern Orpheus Island, southern Orpheus Island and Fantome Island (Fig. 1). These locations were compared with the Lizard Island group. Unlike the Palm Island group, the whole of the Lizard Island group is surrounded by a contiguous reef system and it is therefore considered as a single location (Fig. 1). Although Lutjanus carponotatus is larger than most reef fishes, 2 markrecapture studies at the Lizard Island group suggest that its movements are quite restricted. Davies (1995) trapped fish on sand, reef and patch reef habitats on 7 occasions over a 22 mo period. Of 110 recapture events, $68 \%$ were at the point of release. Inter-habitat movements were primarily restricted to movements between proximal reef and patch reef habitats, with little movement to or across areas of open sand. Davies (1995) concluded that $L$. carponotatus movements are generally less than a few hundred meters, and that fish are highly unlikely to traverse the reef-sand boundary. Similarly, Hilomen (1997) trapped fish on different reef and sand habitats on 7 occasions over a 30 mo period. He found that 
$65 \%$ of all movements were within the same habitat. Of the inter-habitat movements, only $9 \%$ (3\% of all movements) were greater than $150 \mathrm{~m}$ (maximum = $750 \mathrm{~m}$ ), and only 6 movements ( $3 \%$ of all movements) involved sandy areas away from reefs. Tracts of sandy substrate several hundred meters wide separate the Palm group islands and the locations at either end of Orpheus Island joined by contiguous reef are separated by more than $6 \mathrm{~km}$ (Fig. 1). In light of the movement studies of Davies (1995) and Hilomen (1997), and assuming that movement patterns at the Palm Island group are similar to those at the Lizard Island group, the Palm Island group locations were considered unlikely to experience extensive inter-mixing beyond settlement and therefore to represent distinct populations.

The 2 island groups examined in this study are located in different regions of the GBR (Lizard Island group is at approximately $14^{\circ} \mathrm{S}$; Palm Island group is at approximately $19^{\circ} \mathrm{S}$ ) and on different continental shelf positions (Lizard Island group is a mid-shelf complex; Palm Island group is an inshore complex). This means that the 'between island groups' comparisons are confounded by spanning 2 different types of spatial scales. Therefore, comparisons are discussed in relative terms. In other words, differences in population biology are compared on the large versus small scale (i.e. between the island groups versus within the Palm Island group), but the large-scale patterns are not conclusively identified as strictly inter-regional or cross-shelf differences.

Each location was further divided into 3 sites for underwater visual censuses and these sites were divided into 3 reef zones. Reef zones corresponded to the reef flat, upper reef slope and deeper reef slope. Depths defining each zone differed between locations based upon local topography, but each zone within a site was restricted to a $2 \mathrm{~m}$ depth range with at least $2 \mathrm{~m}$ separating zones within each site. No depths exceeded $12 \mathrm{~m}$. Sites within locations were approximately $250 \mathrm{~m}$ long and between 20 and $100 \mathrm{~m}$ wide depending upon the spacing of reef zones. This study therefore examined most aspects of population biology on 2 spatial scales: between the island groups (100s of $\mathrm{km}$ ) and within the Palm Island group (10s of $\mathrm{km}$ or less). Additionally, density differences were examined on 2 smaller scales: among sites within each location (100s of $\mathrm{m}$ ) and among reef zones within each site (10s of $\mathrm{m}$ ).

Sampling methods, sample sizes and age determination. Specimens of Lutjanus carponotatus were collected by spear fishing on the reef slopes at each location. Fish were targeted as sighted, without preference based on body size, in order to collect as representative a sample as possible. Collections at the Palm Island group were made once per month over the course of
1 yr from April 1997 through March 1998. Collections at the Lizard Island group were made in October 1997 and supplemented with 18 additional specimens collected in April 1999. Fork length (FL) to the nearest $\mathrm{mm}$ and whole body weight to the nearest $\mathrm{g}$ were measured for each specimen. Sagittal otoliths were removed, cleaned in freshwater and ethanol, and stored for later analyses.

In this study, total mortality rate is the parameter with the lowest precision specific to sample size, requiring nearly 300 samples to reach a precision of $10 \%$, but reaching $15 \%$ precision between 100 and 150 samples (Kritzer et al. 2001). Therefore, $\mathrm{n}=100$ fish was chosen as a cost-effective minimum sample size for each location. Final sample sizes for the 5 locations were 161 for Pelorus Island, 172 for northern Orpheus Island, 129 for southern Orpheus Island, 103 for Fantome Island and 136 for the Lizard Island group.

The age of each specimen was estimated in order to generate population age structures and age-based mortality and growth parameters. Annual formation of macroincrements in Lutjanus carponotatus otoliths has been validated (Cappo et al. 2000). To determine whether more time- and cost-effective whole otolith readings could be used for any specimens, age estimates from sectioned otolith readings were compared with the deviation between whole and sectioned otolith readings for 251 specimens from this and other collections of L. carponotatus. This comparison was used to select a maximum age beyond which whole otolith readings were deemed unreliable. To best capitalize on the efficiency of whole readings and the accuracy of sectioned readings, whole readings were used for all specimens except those for which any of 3 independent whole readings was greater than the selected cut-off age (10 yr; see 'Results') or for which there was no agreement between at least 2 of the 3 independent whole otolith readings. If there was agreement between at least 2 out of 3 whole or sectioned readings, as appropriate, that value was taken as the age estimate. Ferreira \& Russ (1994) describe the whole and sectioned otolith preparation and reading methods used herein.

Underwater visual censuses (UVC). Censuses were conducted at the Palm Island group locations in July 1999 and at the Lizard Island group in July 2000 to estimate densities and size structures. Plywood models resembling the silhouette of Lutjanus carponotatus and ranging in size from 110 to $360 \mathrm{~mm}$ FL were used to improve the estimation of fish sizes. Before censuses commenced at either island group, assistants laid out 4 lines of 5 to 10 models affixed to twine. The author swam along 1 line, assigned the models to $20 \mathrm{~mm}$ FL size classes, swam behind the line where actual lengths were labeled, and compared estimated and 
actual lengths. Using this comparison to correct biases, the next line was estimated. Censuses immediately followed this training at the Lizard Island group. This procedure was repeated using 2 lines of 8 models each prior to censuses at each Palm Island group location. Predicted model lengths were regressed against actual lengths for successive sets of 2 lines (pooled to achieve adequate sample size) with $y$-intercepts set at 0 . The $95 \%$ confidence interval was calculated for each slope to assess its deviation from 1.

The census design consisted of three $50 \times 5 \mathrm{~m}$ transects swum on SCUBA in each reef zone in each site within each location. The transect size was that recommended for large reef fish on the GBR by Mapstone \& Ayling (1998). Transects were swum roughly parallel to shore and spaced apart by at least $30 \mathrm{~m}$ within zones. While swimming at a slow pace and laying out the $50 \mathrm{~m}$ transect tape, all Lutjanus carponotatus observed within $2.5 \mathrm{~m}$ either side of the tape were counted and assigned to $20 \mathrm{~mm}$ FL size classes.

Population density and structure. Density estimates were compared between locations by a 3-factor analysis of variance (ANOVA), with fixed factors Location and Zone and random factor Site (nested within Location). Pairwise comparisons were then made among locations by Tukey's test. No arbitrary significance level was chosen for the density ANOVA or any statistical test because no meaningful criteria exist by which to select such a level (Johnson 1999). Instead, statistical tests were used to discern degrees of variation in different traits on different scales rather than to make either/or, different/not different distinctions. However, to simplify presentation of the 10 distinct pairwise comparisons, only differences at the $\alpha=0.05$ level are reported.

Log-linear models were used to compare length frequency distributions between censused and collected samples for each location separately. The degree of difference between the 2 methods at each location was assessed on the basis of the likelihood-ratio chisquared statistic (l.r. $\chi^{2}$ ) for the Method $\times$ Size Class interaction. Size and age structures of the collected samples were also compared between the locations using log-linear models based on the strength of the Location $\times$ Size Class and Location $\times$ Age Class interactions. In each test, size or age classes were pooled to achieve the recommendations of no zero values and no more than $20 \%$ of cells with values less than 5 (Zar 1984). This resulted in 7 size classes for the betweenmethod comparisons ( $\leq 160 \mathrm{~mm}, 180 \mathrm{~mm}, \ldots, 260 \mathrm{~mm}$, $\geq 280 \mathrm{~mm}$ ), and 9 size classes $(\leq 140 \mathrm{~mm}, 160 \mathrm{~mm}, \ldots$, $280 \mathrm{~mm}, \geq 300 \mathrm{~mm})$ and 10 age classes $(1,2, \ldots, 8,9-10$, $\geq 11$ ) for the among-locations comparisons.

The Palm Island group samples were collected monthly over the course of $1 \mathrm{yr}$ and the Lizard Island group samples were collected in October 1997 and supplemented in April 1999. This temporal spacing of sampling, though limited, has the potential to mask important aspects of the age structure by spreading single cohorts over 2 or more age classes. This possibility was examined by re-constructing age structures using fishes' likely ages at the start of the sampling period assuming annulus formation dates in August, September or October, as estimated for Lutjanus carponotatus and 9 congeneric lutjanids on the central GBR (Cappo et al. 2000).

Mortality. Total instantaneous mortality rates, $Z$, were estimated for each location by age-based catch curves, which entail linear regression of natural logtransformed frequency on age (Ricker 1975). $Z$ is estimated as the absolute value of the regression slope. Catch curves were fitted from the modal age class through to the oldest age class that was preceded by no more than 2 consecutive 0 frequencies. Mortality rates were compared among locations by analysis of covariance (ANCOVA). Pairwise comparisons using Tukey's test (Zar 1984) were performed to discern the most important sources of strong differences detected by ANCOVA, and, again for purposes of presentation, differences at the $\alpha=0.05$ level are reported. Annual percentage survivorship, $S$, was estimated for each location as: $S=100 \times \exp (-Z)$.

Somatic growth. The relationship between fork length, $L$, and whole body weight, $W$, was described by a power function of the form $W_{L}=a \times L^{b}$. Somatic growth in length and weight were modeled using von Bertalanffy growth functions (VBGF), $L_{t}=L_{\infty}(1-$ $\exp \left(-K\left(t-t_{0}\right)\right)$ and $W_{t}=W_{\infty}\left(1-\exp \left(-K\left(t-t_{0}\right)\right)^{3}\right.$, where $L_{t}$ and $W_{t}$ are length and weight at age $t_{1} L_{\infty}$ and $W_{\infty}$ are the mean asymptotic length and weight, $K$ is the growth coefficient specific to each model, and $t_{0}$ is the age at which a fish has hypothetical length or weight of 0 .

A VBGF was fitted by nonlinear least-squares regression of fork length or whole body weight on age for each Palm Island group location and the Lizard Island group. Estimation of VBGF parameters can be sensitive to exclusion of younger and smaller fish (see Ferreira \& Russ 1994 and Craig et al. 1997 for empirical examples), so a common $t_{0}$ of $-0.049 \mathrm{yr}$ estimated by analysis of early growth of Lutjanus carponotatus (Kritzer 2001) was used in all models. Growth parameters were compared by plotting $95 \%$ confidence regions of the parameters $K$ and $L_{\infty}$ (Kimura 1980) for each location and examining their degree of overlap.

Abundance and biomass. The GIS Section of the Great Barrier Reef Marine Park Authority provided coarse estimates (to the nearest $\mathrm{km}^{2}$ ) of reef area at each location. These were used in conjunction with the demographic data to estimate absolute abundance, areaspecific biomass and overall biomass at each location. 
Censuses at the Palm Island group locations were restricted largely to the sheltered sides of the islands while those at the Lizard Island group only included 1 exposed site (Fig. 1). However, previous studies on the central (Newman et al. 1997) and northern (Mapstone et al. 1998) GBR have found that Lutjanus carponotatus does not exhibit differences in density among habitats within reefs, so densities were assumed to be representative of the whole of each island. Abundance at each location was estimated as $N=\bar{d} \times A$, where $\bar{d}$ is the mean density and $A$ is the reef area.

Biomass was estimated by 2 methods. The first method employed the size structure observed in the collections with biomass estimated as:

$$
B_{0}=\sum_{W=75}^{W_{\max }}\left(p_{W} \times W \times N\right)
$$

where $W$ is $50 \mathrm{~g}$ weight class midpoint, $W_{\max }$ is the maximum observed weight class, $p_{W}$ is the proportion in weight class $W$, and $N$ is the estimated abundance. The second method employed the mortality estimates to predict the age structure if recruitment were constant through time. Biomass was then estimated as:

$$
B_{\mathrm{p}}=\sum_{t=2}^{t_{\max }}\left(p_{t} \times W_{t} \times N\right)
$$

where $t$ is age class, $p_{t}$ is the proportion in age class $t_{\text {, }}$ and $W_{t}$ is weight at age $t$ as predicted by the location's VBGF. The $75 \mathrm{~g}$ size class and age class 2 were chosen as the minima as these were the categories at which fish appeared to be fully recruited to the sampling gear and are approximately the size and age at maturity for Lutjanus carponotatus (Kritzer 2001).

Estimates of these types are subject to numerous sources of error, specifically through estimates of reef area, density, growth, mortality and population structure. Despite the numerous sources of uncertainty, standard errors of the abundance and biomass estimates were determined as multiples of the standard errors of the density estimates, the population trait common to all of these measures of overall population size.

\section{RESULTS}

\section{Validity of the UVC data}

The size estimation training conducted in this study proved to be a quick and efficient means of reducing observer biases and suggested that reliable length estimates emerged from the UVC. After the first series of models was estimated at the Palm Island group $\left(r^{2}=0.737\right)$, precision of the estimated model lengths was high ( $\mathrm{r}^{2}$ range: 0.882 to 0.947 ; mean: 0.925$)$. Accu- racy was also high, evidenced by estimated regression slopes that differed from 1 by at most $7.5 \%$ (range: 0.948 to 1.075 ; mean: 1.023 ) and $95 \%$ confidence intervals of the regression slopes that encompassed 1 in all but 1 instance. The 2 size estimation training sessions conducted at the Lizard Island group 1 yr later also showed this pattern of quick improvement of precision and accuracy after the initial series of models $\left(\mathrm{r}^{2}=\right.$ 0.820 , then 0.952; slope $=0.886$, then 1.007).

Preliminary examination of the UVC data revealed a pronounced shift in size structure from the reef flats onto the reef slopes at the Palm Island group (Fig. 2). Mean fork length increased from $173 \mathrm{~mm}$ on the reef flats to $225 \mathrm{~mm}$ and $218 \mathrm{~mm}$ on the upper and deeper reef slopes, respectively. The modal size classes were 160 and $200 \mathrm{~mm}$ on the reef flats, in contrast to $240 \mathrm{~mm}$ for both reef slope strata. Size frequency distributions from all 3 zones overlapped, but the reef flat distribution did not extend beyond the $240 \mathrm{~mm}$ size class, while both the upper and deep reef slope distributions reached the $320 \mathrm{~mm}$ class. These results suggest that Lutjanus carponotatus change primary habitat as they move to larger size classes, a transition that has impor-
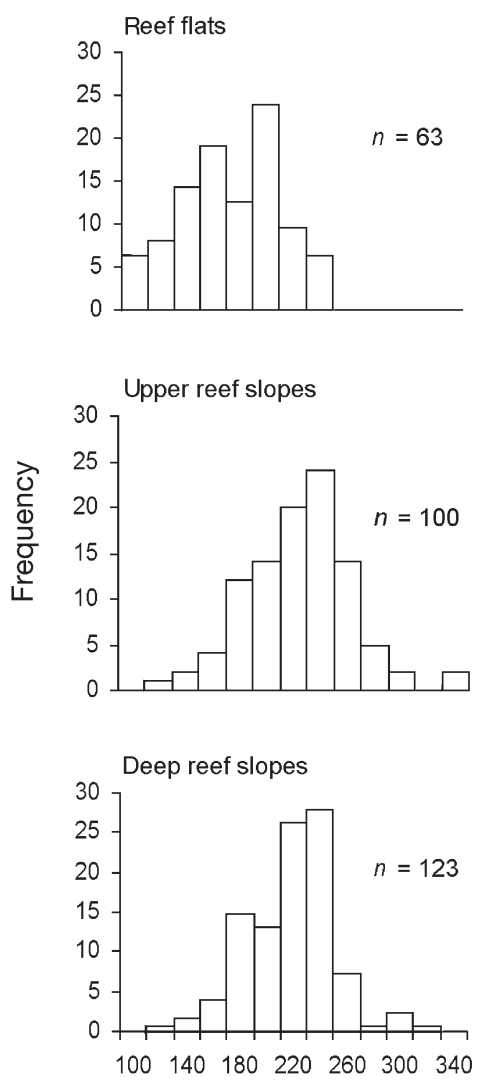

Size class midpoint ( $\mathrm{mm}$ fork length)

Fig. 2. Lutjanus carponotatus. Size frequency distributions among 3 reef zones in the Palm Island group as estimated by underwater visual census 
Table 1. Lutjanus carponotatus. ANOVA results for densities at 5 locations (4 locations within the Palm Island group and the Lizard Island group as a whole) estimated by underwater visual censuses. Location (with 5 levels) and Zone (with 2 levels) are fixed factors. Site (with 15 levels, nested within Location) is a random factor. df: degrees of freedom; MS: mean square; F: F-ratio; p: probability of the data if taken from a single population; $1-\beta$ : observed power of the test. Lines connect locations that are not statistically different at the $\alpha=0.05$ level. For abbreviations of locations see Fig. 3

\begin{tabular}{|c|c|c|c|c|c|}
\hline Source of variation & df & MS & $F$ & $\mathrm{p}$ & $1-\beta$ \\
\hline Location & 4 & 19.67 & 3.14 & 0.065 & 0.604 \\
\hline Zone & 1 & 8.10 & 0.82 & 0.385 & 0.143 \\
\hline Site (Location) & 10 & 6.26 & 0.98 & 0.467 & 0.463 \\
\hline Location $\times$ Zone & 4 & 6.87 & 0.70 & 0.610 & 0.159 \\
\hline Zone × Site (Location) & 10 & 9.83 & 1.55 & 0.145 & 0.699 \\
\hline $\begin{array}{l}\text { Tukey's test for differ- } \\
\text { ences among locations }\end{array}$ & & LG & NOI $\mathrm{S}$ & PI FI & \\
\hline
\end{tabular}

tant implications for the interpretation of subsequent data. Specifically, it raises questions about the ability of a transect size chosen to census larger reef fish to adequately census smaller and more cryptic individuals (e.g. Fowler 1987). Consequently, reef flat data are excluded from subsequent analyses of densities and size structures as the focus was on adult biology.

\section{Density}

Estimates of Lutjanus carponotatus densities on the reef slopes at the 5 locations varied from a low of 0.44 fish per transect at the Lizard Island group to a high of 3.89 fish per transect at Fantome Island (Fig. 3), a more than 8-fold difference. The difference between the mean density at the Lizard Island group and that

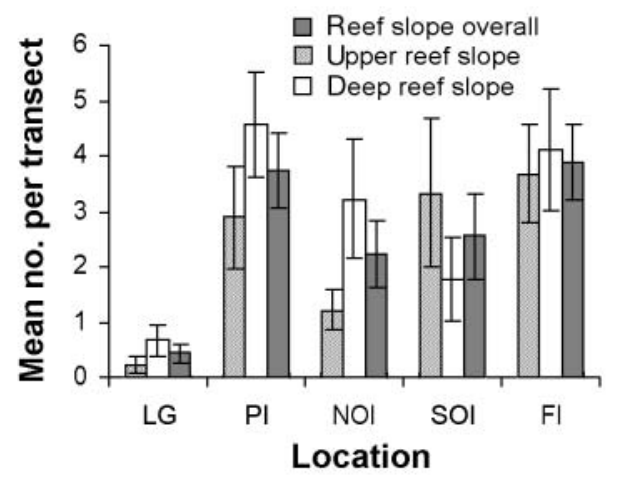

Fig. 3. Lutjanus carponotatus. Mean number per $50 \times 5 \mathrm{~m}$ transect $( \pm \mathrm{SE})$ in 2 reef slope zones and the reef slope overall at 4 locations in the Palm Island group (PI: Pelorus Island; NOI: northern Orpheus Island; SOI: southern Orpheus Island; FI: Fantome Island) and the Lizard Island group as a whole (LG) as estimated by underwater visual census. for the Palm Island group as a whole (3.10 fish per transect) was approximately 7 -fold. Within the Palm Island group, the extreme density estimates at Fantome Island and northern Orpheus Island (2.22 fish per transect) differed by less than 2-fold, but the lowest Palm Island group density at northern Orpheus Island was more than 5 times as great as that at the Lizard Island group (Fig. 3). In contrast to these among-location patterns, density estimates for the upper and deeper reef slopes within each location were within 1 SE of one another for all locations except northern Orpheus Island (Fig. 3). It was therefore not surprising that the strongest signal detected by ANOVA lay in the effect of the Location factor (Table 1). Post-hoc comparisons suggested that pronounced differences exist between Pelorus Island and the Lizard Island group ( $\mathrm{df}=5,10$; $q=5.56 ; \mathrm{p}<0.025)$ and between Fantome Island and the Lizard Island group ( $\mathrm{df}=5,10 ; q=5.84$; $\mathrm{p}<0.025$ ), but all other pairwise comparisons suggested small differences (all $q<3.57$; all $\mathrm{p}>0.1$ ) (Table 1).

Although an order of magnitude difference exists between the mean number of fish per transect at the Lizard Island group and any of the Palm Island group locations, strong signals were only detected for 2 pairwise comparisons (Table 1). Other aspects of the data suggest why stronger statistical results were not obtained despite the pronounced differences in mean densities. Generally low statistical power (Table 1), coefficients of variation ranging from $75 \%$ to $116 \%$, and broad standard errors (Fig. 3) all highlight the tremendous variability in the data. A useful future application of these density data might be to provide estimates of inherent variance and therefore to assist in better designing future sampling programs (Andrew \& Mapstone 1987; e.g. Mapstone \& Ayling 1998). For example, the standard deviation, $s$, of a mean density estimate, $\bar{x}$, can be used with a target precision level, $P$, in the equation $n=(s /(\bar{X} \times P))^{2}$ to estimate the sample size, $n$, required to achieve that precision level. Using values for the pooled Palm Island group data $(s=2.94$; $\bar{X}=3.10$ ), approximately 90 transects per location would be required to achieve $P=0.1$, while only 22 transects would be required to achieve $P=0.2$. While these are likely overestimates of required sample size because pooling the data inflates variance due to spatial variation among locations, 22 transects is close to the 18 transects per location (excluding reef flats) used in this study.

\section{Comparison of size structures between methods and locations}

Overall size structures were generally similar when estimated by UVC and collection of specimens at all 
locations, with the exception of the Lizard Island group, where few fish were censused (Fig. 4). Log-linear models suggested that the interaction between Method and Location was minor for all Palm Island group locations $(\mathrm{df}=6$ for all; Pelorus Island: 1.r. $\chi^{2}=9.03, \mathrm{p}=0.17$; northern Orpheus Island: 1.r. $\chi^{2}=3.98, \mathrm{p}=0.68$; southern Orpheus Island: 1.r. $\chi^{2}=7.36, p=0.29$; Fantome Island: 1.r. $\chi^{2}=8.16, p=0.23$ ). Specific features of the estimated size structures were also generally similar (Table 2). Mean sizes differed little, although modal size classes were 1 size class greater in the UVC size structure for 3 of the 4 locations (Fig. 4, Table 2). This result might be explained by a tendency to overestimate fish sizes during UVC (i.e. regression slopes of training results are generally $>1$ ). The direction, but not the magnitude, of skew in each distribution was consistent between the methods, but there were discrepancies in kurtosis estimates at both Orpheus Island locations (Table 2).

At the Palm Island group, Pelorus Island and northern Orpheus Island exhibited left-hand skew, while southern Orpheus Island and Fantome Island exhibited right-hand skew (Fig. 4, Table 2). This pattern seemed to be driven in part by the length of the left-hand tail of each distribution, with the negatively skewed distributions extending to 2 smaller size classes than the positively skewed distributions (Fig. 4, Table 2). The Lizard Island group distribution was skewed similarly to southern Orpheus Island and Fantome Island (Table 2), but this was more likely due to larger modal
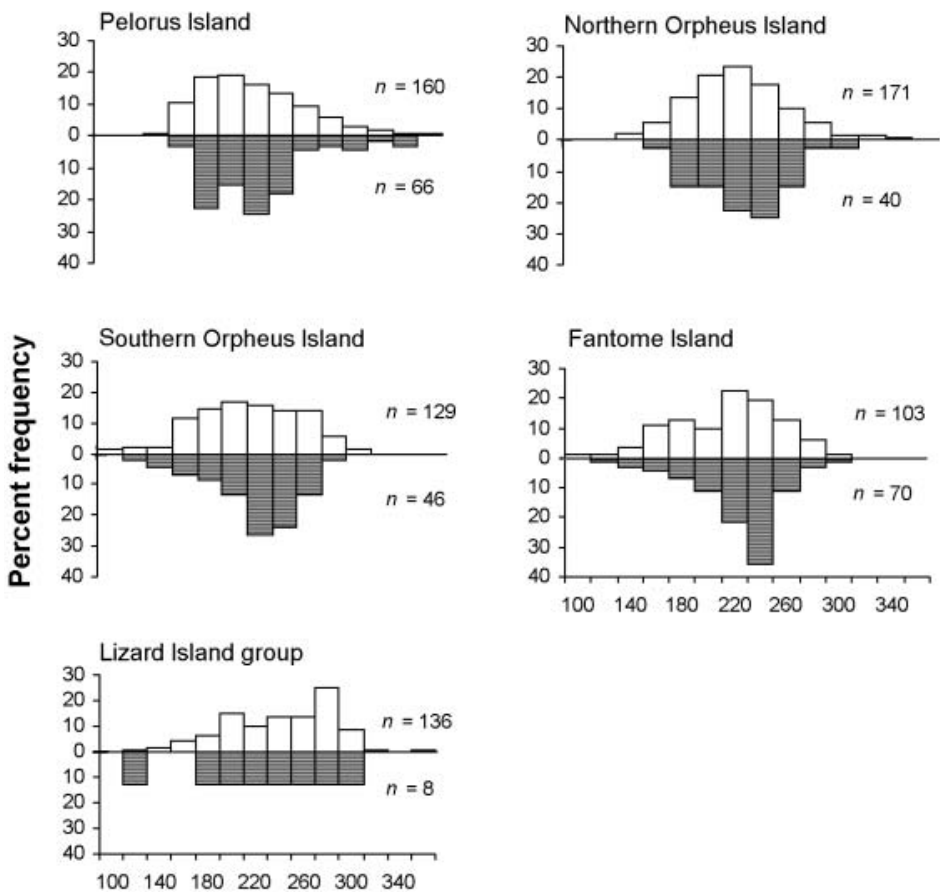

Size class midpoint ( $\mathrm{mm}$ fork length)

Fig. 4. Lutjanus carponotatus. Size frequency distributions at 4 locations in the Palm Island group and the Lizard Island group as a whole as estimated by collection of specimens (open bars) and underwater visual census (shaded bars)

and mean size classes, which were 20 and $60 \mathrm{~mm}$ greater, respectively, than the largest Palm Island group values (Fig. 4, Table 2). In fact, the Lizard Island group contained quite high proportions in the largest size classes $(10.3 \%$ in size classes $>300$ mm; Fig. 4$)$.

Table 2. Lutjanus carponotatus. Statistical parameters for size structures at 4 locations in the Palm Island group and the Lizard Island group as a whole estimated by collection of specimens and underwater visual census. Mean size, modal size class, and range of size classes are in mm fork length. $\mathrm{n}$ : sample size; na: not applicable, as small sample size precludes meaningful parameter estimation

\begin{tabular}{|c|c|c|c|c|c|c|}
\hline Location & $\mathrm{n}$ & Mean & Mode & Range & Skew & Kurtosis \\
\hline \multicolumn{7}{|l|}{ Pelorus Island } \\
\hline Collection & 159 & 217.7 & 200 & $140-360$ & 0.782 & 0.379 \\
\hline Visual census & 66 & 222.1 & 220 & $160-340$ & 1.039 & 0.988 \\
\hline \multicolumn{7}{|c|}{ Northern Orpheus Island } \\
\hline Collection & 171 & 220.5 & 220 & $140-340$ & 0.380 & 0.454 \\
\hline Visual census & 40 & 224 & 240 & $160-300$ & 0.068 & -0.333 \\
\hline \multicolumn{7}{|c|}{ Southern Orpheus Island } \\
\hline Collection & 129 & 211.5 & 220 & $100-300$ & -0.215 & -0.392 \\
\hline Visual census & 46 & 215.7 & 220 & $120-280$ & -0.738 & 0.158 \\
\hline \multicolumn{7}{|l|}{ Fantome Island } \\
\hline Collection & 103 & 214.3 & 220 & $100-300$ & -0.298 & -0.381 \\
\hline Visual census & 70 & 223.1 & 240 & $120-300$ & -0.809 & -0.809 \\
\hline \multicolumn{7}{|c|}{ Lizard Island group } \\
\hline Collection & 135 & 244.6 & 280 & $120-360$ & -0.421 & -0.263 \\
\hline Visual census & 8 & na & na & na & na & na \\
\hline
\end{tabular}


Table 3. Lutjanus carponotatus. Results for the Location $\times$ Size Class interaction term in log-linear models of size structures at 4 locations within the Palm Island group and the Lizard Island group as a whole, including sub-models of selected locations within the Palm Island group. df: degrees of freedom; $^{2}$ : likelihood-ratio chi-squared statistic; $\mathrm{p}$ : probability of the data if taken from a single population

\begin{tabular}{|lrcc|}
\hline Model & df & $\chi^{2}$ & $\mathrm{p}$ \\
\hline $\begin{array}{l}\text { Full model (all locations) } \\
\text { Selected Palm Island group sub-models: }\end{array}$ & 32 & 100.63 & $<0.001$ \\
$\quad$ All locations & 24 & 38.06 & 0.034 \\
$\quad$ Fantome Island excluded & 16 & 25.67 & 0.059 \\
$\quad$ Pelorus Island & & & \\
$\quad$ excluded & 16 & 20.39 & 0.203 \\
$\quad$ and northern Orpheus Island & 8 & 10.77 & 0.215 \\
$\quad$ and southern Orpheus Island & 8 & 14.38 & 0.072 \\
& & & \\
\hline
\end{tabular}

Pelorus Island shared this feature with the Lizard Island group but to a lesser extent $(6.3 \%$ of collected samples and $9.1 \%$ of censused samples in size classes $>300 \mathrm{~mm}$ ) compared with the rest of the Palm Island group (range: 0 to $2.9 \%$; Fig. 4 ).

These size structure differences among the 5 locations were clearly detected by log-linear models (Table 3). The most likely cause of this pronounced result is the shift toward larger size classes at the Lizard Island group (Fig. 4, Table 2). Analysis of a submodel excluding the Lizard Island group confirmed that it was the main source of the detected differences, but revealed remaining differences within the Palm Island group (Table 3). Further analyses suggested that this was driven by differences between Pelorus and Fantome Islands, given that sub-models excluding either indicated more similarity (Table 3). Still, the submodel containing Pelorus Island and the Orpheus

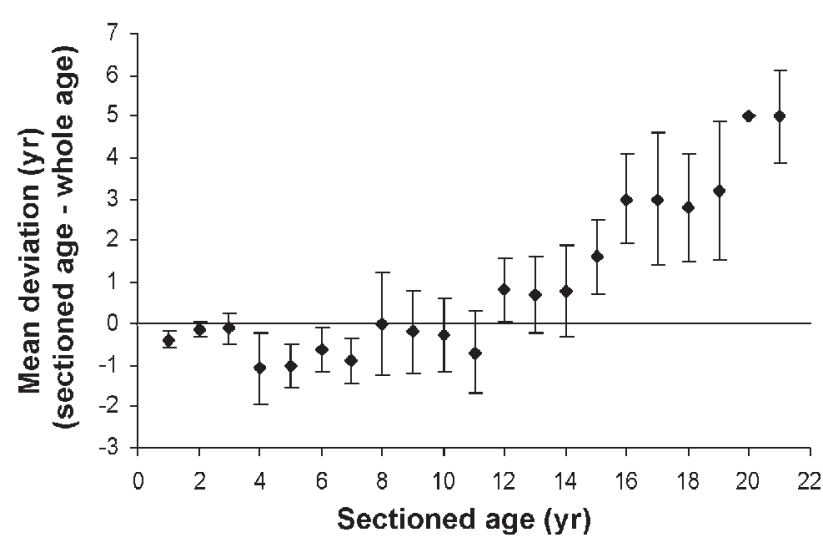

Fig. 5. Lutjanus carponotatus. Mean deviation $( \pm 95 \%$ confidence interval) between age estimates from sectioned and whole otoliths against sectioned age estimates for 251 specimens
Island locations retained some suggestion of differences, likely due to a degree of dissimilarity between Pelorus Island and southern Orpheus Island (Table 3).

\section{Age determination}

The mean deviation between whole and sectioned otolith readings was between 0 and -1 up to Sectioned Age 11 (Fig. 5). Beamish (1979) and Ferreira \& Russ (1994) similarly found that whole otolith readings seem to overestimate age of some younger specimens. However, Ferreira \& Russ (1994) also note that the innermost annuli were often poorly defined in sectioned otoliths compared to whole otoliths. The first annulus in otolith sections of Lutjanus carponotatus was often faint and difficult to discern, which corroborates the findings of Ferreira \& Russ (1994) and suggests that whole otolith readings might provide better age estimates for young fish. At older ages, the deviation between whole and sectioned otolith readings was generally $>0$ and quickly diverged to values of 3 or more at the oldest age classes (Fig. 5). This pattern of rapid divergence after around $10 \mathrm{yr}$ of age is similar to that reported by both Beamish (1979) and Ferreira \& Russ (1994). Given these results, a whole otolith reading of 10 was selected as the maximum beyond which otoliths were read sectioned.

\section{Age structures and mortality}

The Palm Island group locations all exhibited a pattern of exponential decline in age frequency with age beyond the mode of $2 \mathrm{yr}$, without marked peaks and troughs, up to a maximum age of 16 to $18 \mathrm{yr}$ (Fig. 6). The most prominent difference among the Palm Island group age structures was the strength of the modal age class, with Pelorus Island exhibiting a less pronounced mode than its neighbors (Fig. 6). Age structures reconstructed with ages of specimens corrected to the start of the sampling regime did not alter the character of these distributions. In contrast, correcting the ages of the April 1999 Lizard Island group samples to their ages at the time of the initial October 1997 collection shifted the modal age class from Age 2 to Age 3. However, the difference was not great (proportions in the 2 age classes differed by at most $4 \%$ in either construction), so the ages were considered as enumerated. This difference, though minor, highlights both the need to consider timing of sampling when analyzing data and the difficulty of treating continuous variables such as age as discrete entities.

Other aspects of the Lizard Island group age structure were consistent regardless of whether the April 
1999 specimens' ages were corrected to 1997 or taken as estimated. The maximum age was $17 \mathrm{yr}$, and age frequencies steadily declined from the mode until Age 7, similar to the Palm Island group locations (Fig. 6). However, a second mode was then encountered at Age 8, followed by high frequencies for Ages 9 through 11 (Fig. 6). Consequently, log-linear models not surprisingly suggested large differences between age structures when all locations were included ( $\mathrm{df}=36$, l.r. $\chi^{2}=93.15$, $\mathrm{p}<0.001$ ), but not in a sub-model containing only Palm Island group locations ( $\mathrm{df}=27$, l.r. $\chi^{2}=35.07, \mathrm{p}=0.14$ ).

Estimates of total mortality rate, $Z$, ranged from $0.16 \mathrm{yr}^{-1}$ at Fantome Island to $0.29 \mathrm{yr}^{-1}$ at Pelorus Island (Fig. 7), corresponding to 86 and $75 \%$ annual survivorship, respectively (Table 4). ANCOVA suggested large differences in mortality between locations ( $\mathrm{df}=$ $4,64, F=4.04, p=0.006$ ). Multiple comparisons by Tukey's test suggested large differences between Fantome Island and all other Palm Island group locations, but not between Fantome Island and the Lizard Island group (Table 4). Furthermore, Pelorus Island and the Lizard Island group were each similar to northern and southern Orpheus Island, but were quite different from one another (Table 4). The strong cohorts from Ages 8 through 11 in the Lizard Island group age structure had the potential to pull the mortality curve upwards, thereby lowering the slope and underestimating mortality. However, somewhat unexpectedly,
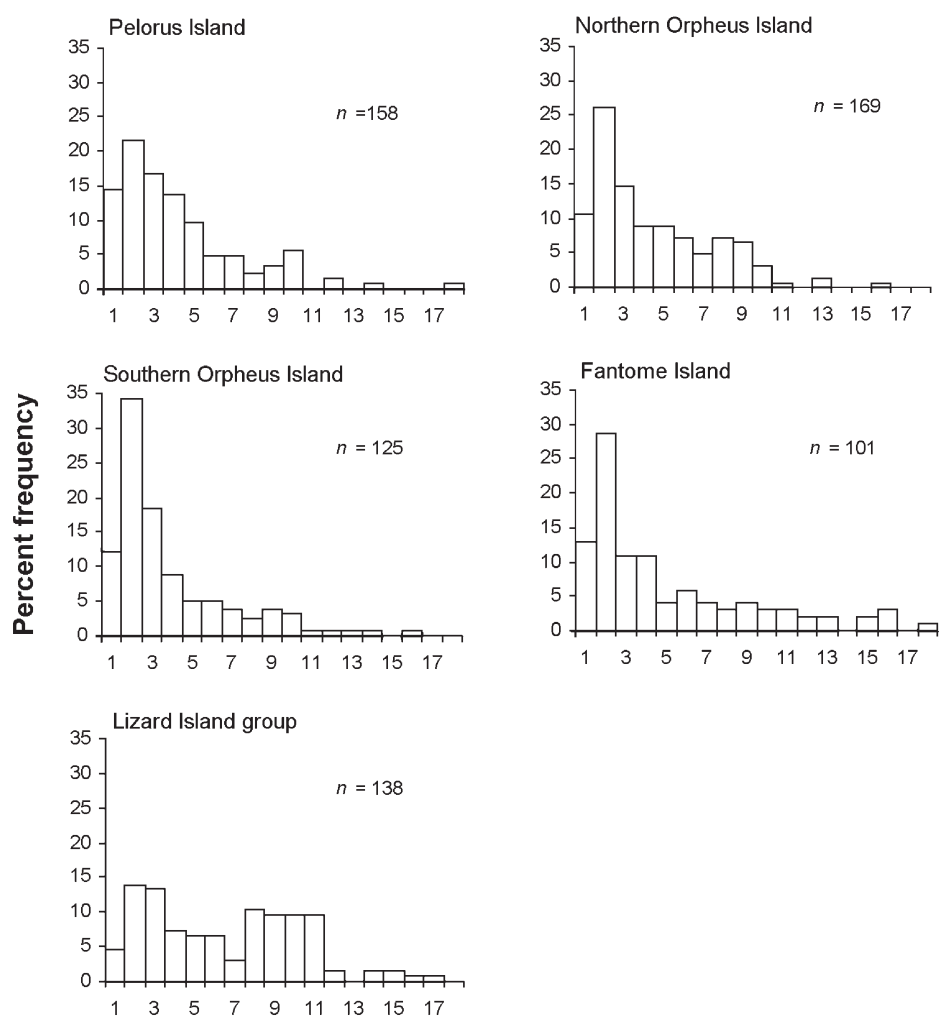

\section{Age class (yr)}

Fig. 6. Lutjanus carponotatus. Age frequency distributions at 4 locations in the Palm Island group and the Lizard Island group as a whole

excluding these 4 age classes resulted in little change of mortality and survivorship estimates $(Z$ estimates differed by $0.005 ; S$ estimates differed by $0.9 \%$ ), but

Table 4. Lutjanus carponotatus. Estimates of population parameters for 4 locations in the Palm Island group and the Lizard Island group, Great Barrier Reef. $Z$ : total instantaneous mortality rate $\left(\mathrm{yr}^{-1}\right) ; S$ : percentage annual survivorship $\left(S=100 \mathrm{e}^{-Z}\right) ; K$ : von Bertalanffy growth coefficient $\left(\mathrm{yr}^{-1}\right) ; L_{\infty}$ : mean asymptotic fork length $(\mathrm{mm}) ; W_{\infty}$ : mean asymptotic whole body weight $(\mathrm{g})$. Also presented are results of multiple comparisons among $Z$ estimates by Tukey's test

\begin{tabular}{|c|c|c|c|c|c|c|}
\hline \multirow[t]{2}{*}{ Location } & \multirow{2}{*}{\multicolumn{2}{|c|}{$Z(S)$}} & \multicolumn{2}{|c|}{ Growth in length ${ }^{\mathrm{a}}$} & \multicolumn{2}{|c|}{ Growth in weight ${ }^{\mathrm{a}}$} \\
\hline & & & $K$ & $L_{\infty}$ & $K$ & $W_{\infty}$ \\
\hline \multicolumn{7}{|l|}{ Palm Island group: } \\
\hline Pelorus Island & $0.291(74.7 \%)$ & & 0.689 & 261.7 & 0.489 & 428.2 \\
\hline Northern Orpheus Island & $0.267(76.6 \%)$ & & 0.827 & 247.3 & 0.618 & 318.7 \\
\hline Southern Orpheus Island & $0.220(80.2 \%)$ & & 0.711 & 250.3 & 0.519 & 346.2 \\
\hline Orpheus Island pooled & $0.244(78.3 \%)^{b}$ & & $0.768^{\mathrm{c}}$ & $248.9^{c}$ & $0.575^{\mathrm{c}}$ & $328.5^{c}$ \\
\hline Fantome Island & $0.150(86.1 \%)$ & & 0.776 & 246.2 & 0.701 & 302.9 \\
\hline Lizard Island group & $0.179(83.6 \%)$ & & 0.540 & 273.1 & 0.403 & 459.9 \\
\hline Tukey's test for differences in $Z^{\mathrm{d}}$ & $\underline{\mathrm{PI}}$ & SOI & NOI LG & FI & & \\
\hline \multicolumn{7}{|c|}{${ }^{\mathrm{a}} \mathrm{A}$ common $t_{0}$ of -0.049 was used in all growth models } \\
\hline \multicolumn{7}{|c|}{${ }^{\mathrm{b}}$ Calculated as the mean of the 2 Orpheus Island location estimates } \\
\hline \multicolumn{7}{|c|}{${ }^{\mathrm{C}}$ Calculated by fitting growth curves to the combined Orpheus Island locations data } \\
\hline${ }^{\mathrm{d}}$ Lines connect locations that are & tistically different at & & $=0.05$ level & & & \\
\hline
\end{tabular}


these age classes are likely the cause of the highest degree of variability in the Lizard Island group mortality estimate (Fig. 7).

\section{Somatic growth}

The equation relating length to weight was $W_{L}=$ $1.19 \times 10^{-5} L^{3.08}$. This approximately cubic relationship did not differ in space and accounted for a great deal of the variance in weight $\left(\mathrm{r}^{2}=0.98\right)$.

Growth curves for the Palm Island group locations and the Lizard Island group all exhibit the pronounced asymptote previously reported as characteristic of Lutjanus carponotatus (Davies 1995, Newman et al. 2000). The $K-L_{\infty} 95 \%$ confidence regions for the Palm Island group locations span a similar range of values in the $K$ direction (Fig. 8). However, the Pelorus Island confi-
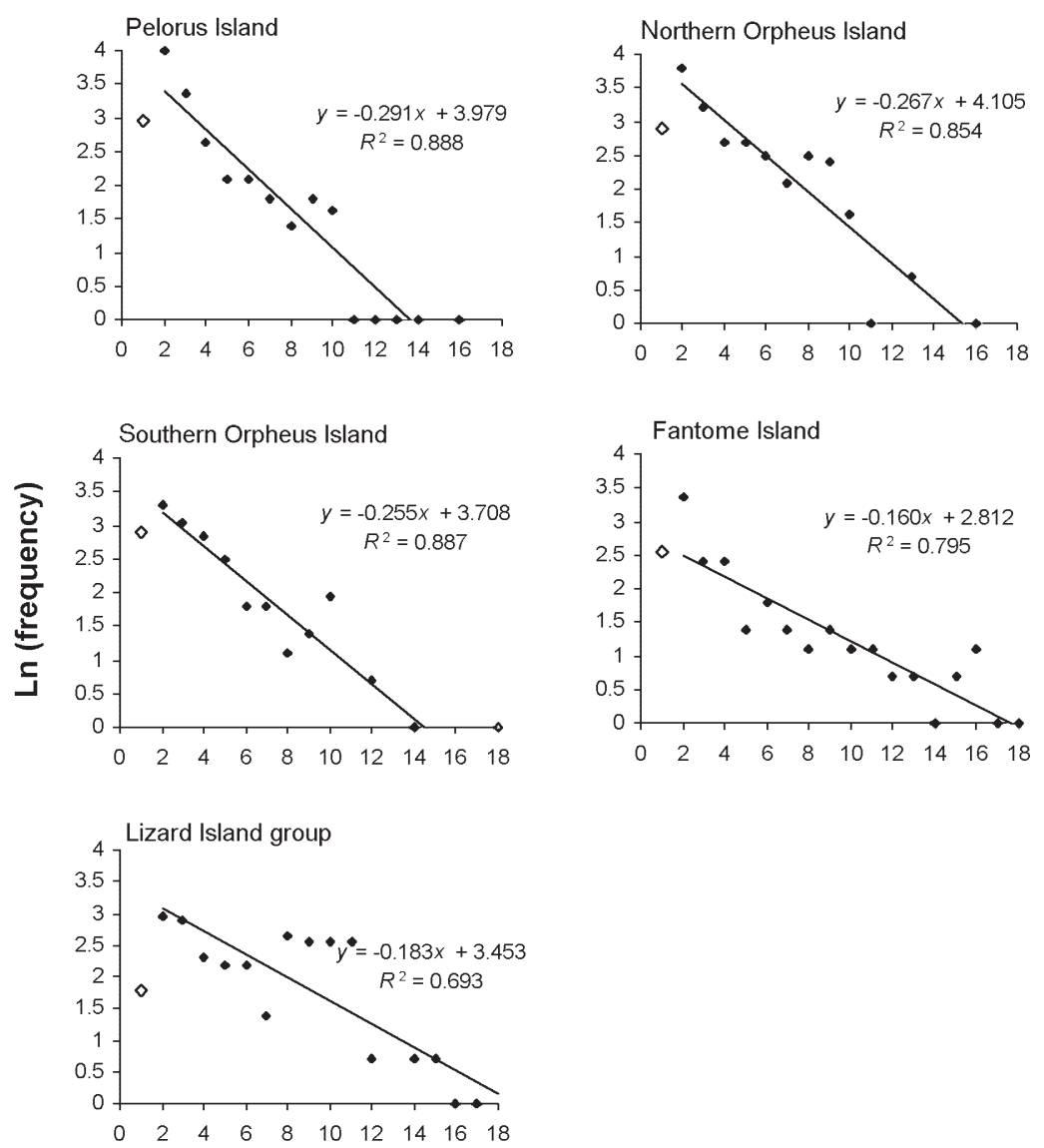

Age class (yr)

Fig. 7. Lutjanus carponotatus. Age-based catch curves at 4 locations in the Palm Island group and the Lizard Island group as a whole. Age classes represented by open symbols were excluded from the analysis. Total instantaneous mortality rate, $Z$, is estimated as the absolute value of the regression slope dence region separates to some extent, though not completely, from the other Palm Island group locations with respect to $L_{\infty}$ and spans a range of values similar to those spanned by the Lizard Island group (Fig. 8).

The differences in $L_{\infty}$ between the Lizard Island group, Pelorus Island and the rest of the Palm Island group, while quite clear (Fig. 8), are not large. The $L_{\infty}$ estimate for the Lizard Island group is only $10.9 \%$ greater than the smallest value within the Palm Island group, Fantome Island, while the Pelorus Island estimate is only $6.3 \%$ greater (Table 4 ). However, due to the cubic relationship between length and weight, the differences become more pronounced when growth is examined in terms of weight. Although the degree of individual variability in size at age also drastically increases, even more distinct differences emerge in the $K-W_{\infty} 95 \%$ confidence regions between Pelorus Island and the rest of the Palm Island group (Fig. 9). The Pelorus Island confidence region is more similar to the Lizard Island group for growth in weight (Fig. 9) than for growth in length (Fig. 8), and their asymptotic size estimates are 41.4 and $51.8 \%$ greater, respectively, than the Fantome Island estimate (Table 4).

\section{Abundance and biomass}

The resolution of the GIS data did not allow reef area to be partitioned into reef slope and reef flat. Because adult population structures and demographic rates were used to calculate the measures of overall population size but the reef flats seem to be juvenile habitat more so than adult habitat (Fig. 2), these figures are likely to be overestimates. However, reef flats are a small proportion of the total reef area at all locations so the extent of overestimation is likely not to be severe. Furthermore, the estimates still effectively serve to illustrate how population traits interact to determine overall population size and to enable relative comparisons among the locations irrespective of the degree of overestimation. Also, due to the similarity of their density (Fig. 3), population structure (Figs. 4 \& 6, Tables 2 \& 3), mortality (Fig. 7, Table 4), and growth (Figs. 8 \& 9, Table 4) estimates, the 2 Orpheus Island locations' data were pooled to produce estimates of abundance and biomass for the Island as a whole. 
Estimates of these overall population size measures at all islands had large standard errors (Table 5) due to the variability in the density estimates (Fig. 3) on which the standard errors are based. The 2 methods used to generate these measures produced generally similar results. This is not surprising given that the population traits used in each method (i.e. population structure versus demographic rates) are alternative analyses of a common age-length data set. Still, the differences that did arise between the resulting estimates of biomass highlight important considerations when using either observed population structure or that predicted from demographic processes. For the 3 Palm Island group locations, the estimates based upon demographic processes were higher than those based upon observed size structures (Table 5). This might be explained by slight overestimation of body size at young age classes (i.e. many data points lying below the fitted VBGFs; Fig. 9) that comprise the bulk of the population (Fig. 6). In contrast, the Lizard Island group estimates generated using demographic processes were lower than those generated using observed size structures (Table 5). This is likely to be due to lack of consideration of the strong series of older age classes (Fig. 6) when using mean growth and mortality rates.

Abundance estimates were ordered according to reef area within the Palm Island group, but the relative differences
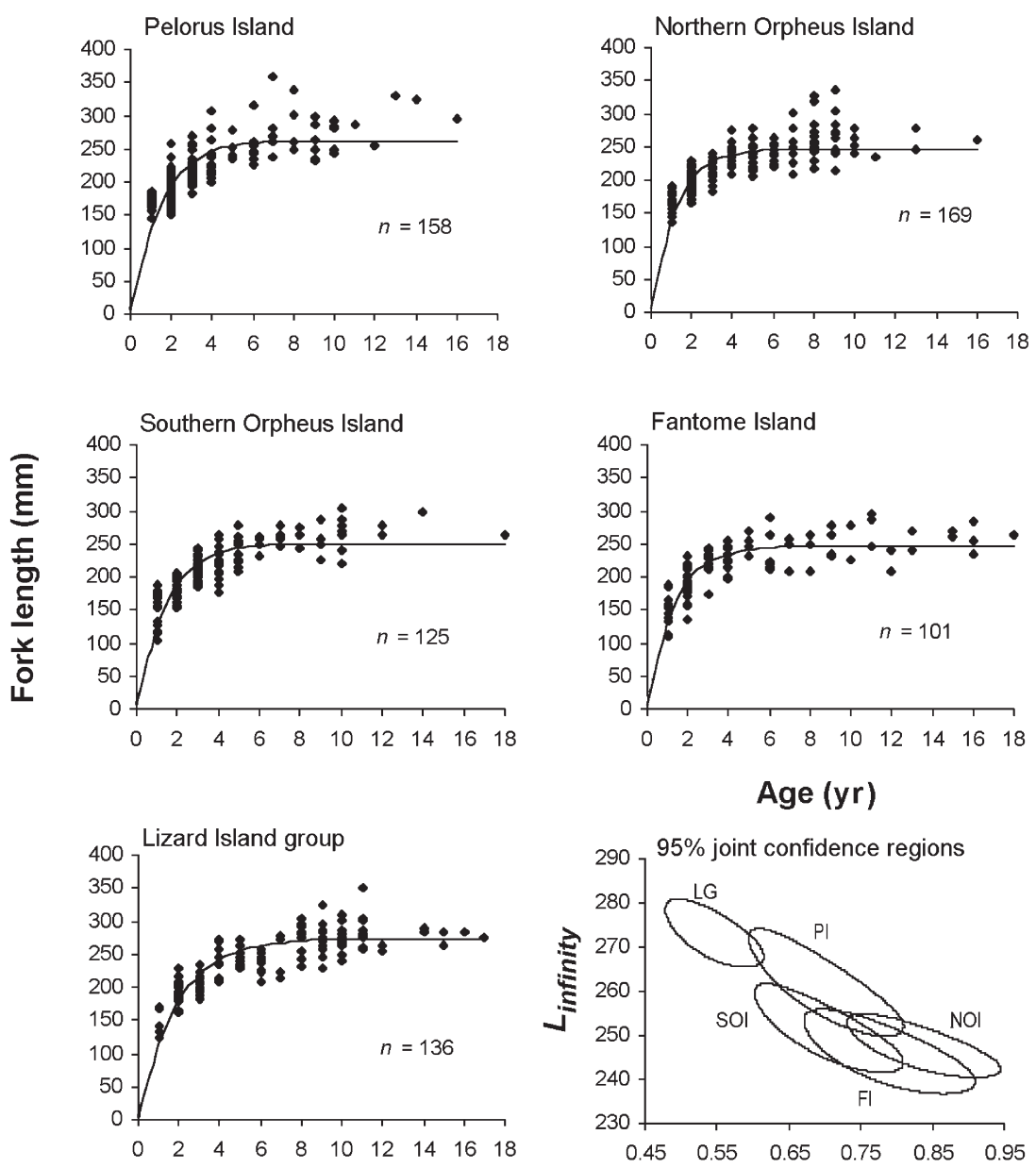

Age (yr)

Fig. 8. Lutjanus carponotatus. Length at age data and estimated von Bertalanffy growth curves and $95 \%$ joint confidence regions of the parameters $K$ and $L_{\infty}$ for at 4 locations in the Palm Island group and the Lizard Island group as a whole

Table 5. Lutjanus carponotatus. Estimates of population size measures at 3 islands within the Palm Island group and at the Lizard Island group, Great Barrier Reef. Estimates were determined using both observed size structures $\left(B_{0}\right)$ and size structures predicted by growth and mortality acting upon constant recruitment $\left(B_{\mathrm{p}}\right)$. One standard error, based on the standard errors of the density estimates, is indicated in brackets. Due to their similarity, data for the 2 locations at Orpheus Island were pooled and estimates for the Island as a whole were generated. See text for further details. $A$ : reef area $\left(\mathrm{km}^{2}\right)_{;} N$ : abundance; $B / A$ : biomass km ${ }^{-2}$; $B$ : biomass $(\mathrm{kg})$

\begin{tabular}{|c|c|c|c|c|c|c|}
\hline \multirow[t]{2}{*}{ Location } & \multirow[b]{2}{*}{$A$} & \multirow[b]{2}{*}{$N$} & \multicolumn{2}{|c|}{ Observed size structure } & \multicolumn{2}{|c|}{ Demographic processes } \\
\hline & & & $B_{\mathrm{o}} / A$ & $B_{\mathrm{o}}$ & $B_{\mathrm{p}} / A$ & $B_{\mathrm{p}}$ \\
\hline \multicolumn{7}{|l|}{ Palm Island group: } \\
\hline Pelorus Island & 1 & $\begin{array}{l}14889 \\
(2702)\end{array}$ & $\begin{array}{l}3139 \\
(570)\end{array}$ & $\begin{array}{l}3139 \\
(570)\end{array}$ & $\begin{array}{l}3890 \\
(706)\end{array}$ & $\begin{array}{l}3890 \\
(706)\end{array}$ \\
\hline Orpheus Island & 7 & $\begin{array}{c}66889 \\
(13538)\end{array}$ & $\begin{array}{l}1966 \\
(398)\end{array}$ & $\begin{array}{l}13760 \\
(2785)\end{array}$ & $\begin{array}{l}2235 \\
(452)\end{array}$ & $\begin{array}{l}15643 \\
(3166)\end{array}$ \\
\hline Fantome Island & 2 & $\begin{array}{l}31111 \\
(5484)\end{array}$ & $\begin{array}{l}3298 \\
(581)\end{array}$ & $\begin{array}{c}6596 \\
(1163)\end{array}$ & $\begin{array}{l}3969 \\
(700)\end{array}$ & $\begin{array}{r}7938 \\
(1399)\end{array}$ \\
\hline Lizard Island group & 9 & $\begin{array}{l}16000 \\
(5980)\end{array}$ & $\begin{array}{c}545 \\
(204)\end{array}$ & $\begin{array}{c}4901 \\
(1832)\end{array}$ & $\begin{array}{c}512 \\
(191)\end{array}$ & $\begin{array}{c}4608 \\
(1722)\end{array}$ \\
\hline
\end{tabular}



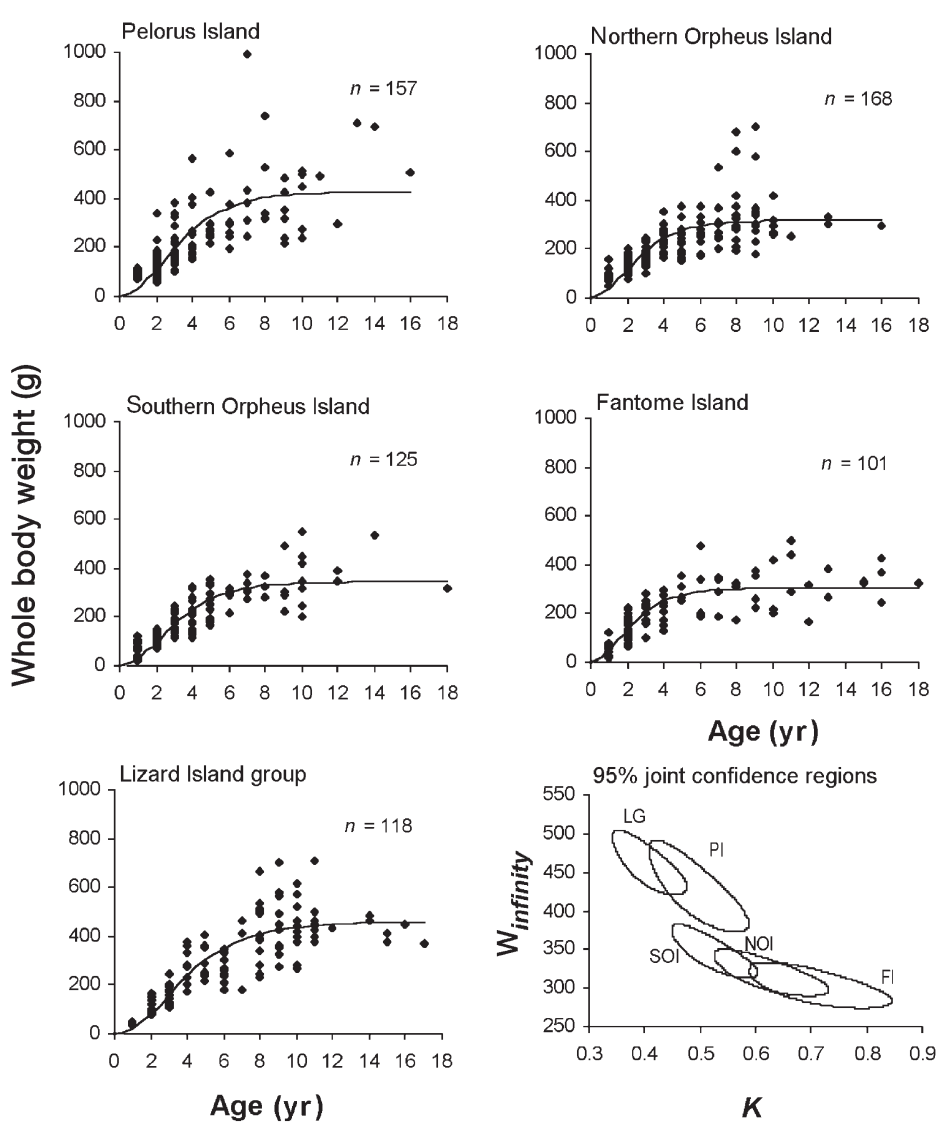

Fig. 9. Lutjanus carponotatus. Weight at age data and estimated von Bertalanffy growth curves and $95 \%$ joint confidence regions of the parameters $K$ and $W_{\infty}$ at 4 locations in the Palm Island group and the Lizard Island group as a whole

did not approximate the differences in reef area due to the differing density estimates (Table 5, Fig. 3). In contrast, the Lizard Island group's estimated abundance was close to the lowest despite this location having the largest area of reef. The estimates suggest that numbers of fish at each island were of a similar order of magnitude $\left(10^{5}\right)$. Adult biomass estimates at these islands ranged from 3 to 15 metric tons, again with the Palm Island group locations ordered according to reef area (Table 5). Assessing population size in terms of biomass reduced the disparity between the Lizard Island group and the Palm Island group locations relative to comparisons of density or abundance.

\section{DISCUSSION}

\section{Spatial patterns in the population biology of Lutjanus carponotatus}

All population traits of Lutjanus carponotatus examined in this study, barring longevity, exhibited some appreciable degree of difference between the 2 island groups, but differences in size structure, mortality and growth were also evident among proximal reefs within the Palm Island group. The smaller scale-differences in growth and associated differences in size structures are not surprising given that growth is the trait likely to be most responsive to differences in the immediate environment (Jones 1991). In fact, on the GBR, other long-lived gonochores with a pronounced asymptote in their growth curve exhibit similar differences in asymptotic size among neighboring populations (Hart \& Russ 1996, Newman et al. 1996), while differences in growth rate have been found in small-bodied species on even smaller scales (Gladstone \& Westoby 1988, Pitcher 1992). Unlike growth, the greatest differences in mortality were not found between the island groups but rather within the Palm Island group, as the Lizard Island group was similar to 3 of the 4 Palm Island group locations, but Fantome Island was different from its 3 neighbors. Mortality is inherently more difficult to estimate than growth (Jones 1991, Kritzer et al. 2001), which might result in apparent differences that are due to methodological and analytical difficulties and not real patterns. However, differences in mortality on relatively small spatial scales have also been reported for other reef fish species (Aldenhoven 1986, Newman et al. 1996, but see Hart \& Russ 1996).

Despite the high amount of variability in the data, differences in mean density were of the greatest magnitude of any population trait examined. Mean densities differed by a factor of nearly 2 within the Palm Island group, but estimates were characterized by uncertainty that obscured the extent of local differences. Other studies suggest that Lutjanus carponotatus does not exhibit density differences between neighboring reefs on the central GBR (Newman et al. 1997) but does so on the northern GBR (Mapstone et al. 1998). However, the differences between the island groups were more pronounced, with at least 2 of the Palm Island group locations showing striking differences from the Lizard Island group. This pattern is consistent with previously reported differences in $L$. carponotatus densities on spatial scales greater than neighboring reefs (Newman et al. 1997, Mapstone et al. 1998). Similar to the density patterns, the data suggest that recruitment patterns vary more widely between the island groups than they do on a local scale, assuming that population age structures retain some information about recruitment histories (Doherty \& Fowler 1994, Russ et al. 1996). 


\section{Possible causes of the spatial patterns}

Where in the early life history the age structure patterns originate cannot be discerned from the existing data. If recruitment to the reef (i.e. settlement of pelagic juveniles) occurs at levels well below the carrying capacity of juveniles, then the age structures reflect variation in larval supply. On the other hand, if larval supply at the Palm Island group locations is closer to the carrying capacity of new settlers, then fluctuations in recruitment to the reef will be smoothed, resulting in more regular recruitment to the adult population and age structures with fewer anomalous peaks and troughs, like those observed. Settlement rates of reef fishes are typically below the level at which density-dependent effects become important but can reach those levels at times (Doherty 2002), so either scenario (less variable settlement rates or variable settlement rates smoothed by densitydependence) is possible for the Palm Island group. If juvenile carrying capacity and demographic rates are similar between the island groups, the adult density differences might suggest settlement rates at the Lizard Island group are generally lower and therefore density-dependent effects do not arise, whereas settlement rates are higher at the Palm Island group and density-dependent effects do arise. Of course, the age structure at the Lizard Island group might also be a product of temporal changes in adult mortality, juvenile mortality or juvenile carrying capacity.

Density-dependent effects on demography of coral reef fishes have been demonstrated, often for juveniles (e.g. Forrester 1995; reviewed by Jones 1991 and Doherty 2002) and less frequently for adults (reviewed by Jones 1991). The data reported herein can be used in a preliminary examination of the potential for density-dependent effects. The 2 locations with the highest densities, Fantome Island and Pelorus Island, exhibited the lowest and highest mortality rates, respectively. The location with the lowest density, the Lizard Island group, exhibited the second-lowest mortality rate, which was quite similar to that of Fantome Island. Therefore, there is no suggestion that adult mortality is affected by density, a general trend among reef fish studies (Jones 1991). On the other hand, the Lizard Island group has the lowest density and the largest asymptotic body size. Although Fantome Island has the highest density and the smallest asymptotic body size, Pelorus Island had a comparable density but the largest asymptotic body size among the Palm Island group locations. Therefore, density might affect adult growth (Jones 1991), but the effects might only be evident when density differs by an order of magnitude or more. Of course, the limited number of locations and confounding environmental differences render these data useful only for generating hypotheses about density-dependence and not for testing hypotheses.

The confounding of inter-regional and cross-shelf spatial scales is an unfortunate shortcoming of the sampling design of this study. Data from inshore reefs on the northern GBR would share a common regional position with the Lizard Island group and a common continental shelf position with the Palm Island group, and therefore could help resolve this ambiguity. Differences in community structure on the GBR have been found to exist along both latitudinal and cross-shelf gradients, with patterns on the latter scale typically being more pronounced (Williams 1983). Emerging data on fish growth examined at larger spatial scales suggest that differences akin to those observed for Lutjanus carponotatus are evident on both inter-regional (Williams 1997) and cross-shelf (Choat 1998, Dudgeon et al. 2000) scales on the GBR. Caley (1995) found that predation pressure is greater on the northern GBR than the southern GBR, which resulted in lower abundance of fishes despite higher recruitment rates. If similar inter-regional differences in predation pressure exist between the northern and central GBR, this would explain the lower densities at the Lizard Island group. Higher predation rates could also explain the larger body sizes at the Lizard Island group if there is greater selective pressure to grow out of smaller and more vulnerable sizes.

Other studies on density (Newman \& Williams 1996, Newman et al. 1997) and growth (Newman et al. 2000) of Lutjanus carponotatus on mid-shelf reefs directly offshore from the Palm Island group report lower density and larger asymptotic body size akin to the Lizard Island group. This suggests that the present study might be detecting cross-shelf differences. If the largescale patterns are a consequence of different positions on the continental shelf, terrigenous influences might be producing the observed differences, particularly in growth. The Palm Island group sits directly offshore from the mouth of the Herbert River. Freshwater outflow from this river and the increased turbidity caused by transported sediments might impose physiological stresses that affect the growth potential of reef fishes. Turbidity has been shown to be an important determinant of growth potential in reef corals (Anthony \& Fabricius 2000), but no-one has looked for effects on reef fishes. Sweka \& Hartman (2001) recently found that increased turbidity lead to higher and more energetically costly activity levels of brook trout Salvelinus fontinalis, which in turn lead to reduced growth rates. In fact, the Palm Island group location with the smallest asymptotic body size, Fantome Island, has an extensive mangrove system along its shore that causes heavy siltation on its reefs and increases the turbidity 
of nearby waters. Therefore, there is a consistent trend both within the Palm Island group and between it and the Lizard Island group of decreasing body sizes with increasing influence of terrestrial and riverine systems. If this hypothesized stress is having an influence, it does not appear to affect mortality and density.

Worldwide, fishing pressure has effected many and varied changes in many fish populations. Fishing can clearly increase mortality and decrease density, and can also alter growth patterns by selectively removing the largest individuals. Fishing does take place on the GBR, including these 2 island groups. Line fishing is permitted on part of the reef system at the Lizard Island group and at southern Orpheus Island. The rest of Orpheus Island is protected from all fishing. Both line and spear fishing are permitted at Pelorus and Fantome Islands. Although Lutjanus carponotatus is a harvested species, it is unlikely that fishing pressure is a direct determinant of these spatial patterns for 2 main reasons. Firstly, fishing pressure at the Lizard Island groups is quite low. The Lizard Island group is approximately $100 \mathrm{~km}$ from Cooktown, the nearest coastal town, which is beyond the range of many recreational fishers. Commercial fishers do not fish the Lizard Island group, likely due to the limited area of reef open to fishing, as well as the presence of a resort and research station and their associated human traffic. Secondly, although L. carponotatus is a harvested species, the extent of harvest is minimal. Like the Lizard Island group, commercial fishers do not fish the Palm Island group. The proximity of the islands to the mainland towns of Ingham and Cardwell attracts the recreational fishing fleet, but these fishers primarily target other species such as coral trouts of the genus Plectropomus, barramundi cod Cromileptes altivelis, maori wrasse Cheilinus undulatus, and larger lutjanids such as mangrove jack Lutjanus argentimaculatus. A study of the catch composition of recreational fishers on the central GBR (Higgs 1993) found that $L$. carponotatus only comprises less than $1 \%$ of the catch, despite being one of the most abundant predators, particularly on inshore reefs (Newman \& Williams 1996).

Fishing pressure might, however, be an indirect determinant of local differences in density within the Palm Island group. The aforementioned primary target species of recreational fishers are larger-bodied fishes and potential predators of both juvenile and adult Lutjanus carponotatus. Density estimates were highest at Pelorus and Fantome Islands, the 2 locations within the Palm group with the least protection from fishing. If populations of these larger predators have been diminished at these locations, L. carponotatus densities might be higher due to relaxation of predation pressure.

\section{Possible consequences of the spatial patterns}

The processes structuring coral reef fish populations are numerous and, when possible, single population traits should not be used to assess overall reproductive potential (e.g. Newman et al. 1996). For example, the density estimate of Lutjanus carponotatus at Fantome Island was approximately 9 times that of the Lizard Island group. However, when body sizes are incorporated through data on growth or size structure, the area-specific biomass differences between these locations are 5- and 8-fold, respectively. Furthermore, when reef size is used to produce overall rather than area-specific estimates, the differences between the Lizard Island group and Fantome Island become less than 2-fold for both abundance and biomass. By all of these metrics, Fantome Island is estimated to support a larger population of L. carponotatus than the Lizard Island group, but the degree of this difference is clearly very different when considered in terms of density, abundance, area-specific biomass or overall biomass.

There is an emerging trend to view coral reef fish ecology within the context of metapopulation ecology. One of the first modeling studies that considered coral reef fish metapopulations (Man et al. 1995) assumed homogeneous demography among subpopulations. However, a more recent study (Crowder et al. 2000) has examined source-sink dynamics and therefore makes the more realistic assumption of demographic heterogeneity among subpopulations. While sourcesink distinctions are useful in theoretical studies like that of Crowder et al. (2000), real subpopulations are more likely to fall along a gradient of reproductive capacity and contribution to overall replenishment (Thomas \& Kunin 1999). These characteristics will be determined by both the population biology of each subpopulation and its position within the connectivity matrix. Insufficient data exist with which to determine the latter for the Lutjanus carponotatus populations examined herein, but the present study can lend insights into reproductive potential. If whole islands are taken as the minimum unit defining a subpopulation, the abundance and biomass measures suggest that Orpheus Island is the most important source of egg production among the Palm Island group locations studied primarily due to its larger size. If, on the other hand, subpopulations are distinguished among portions of habitat within each island's reef system, Pelorus and Fantome Islands will provide more important sources due to their greater area-specific population size measures, assuming these are not a result of fishing pressure on potential predators of $L$. carponotatus. At present, some marine protected areas within the Palm Island group comprise entire islands and others are 
designated as portions of an island's reef system, so either perspective is useful in a management context.

\section{Implications for choice of spatial scale}

The results of this study highlight 3 main points with respect to the question of spatial scale in studies of reef fish population biology. Firstly, the magnitude of differences in population biology typically increases with increasing scale. Densities, size structures, age structures and inferred recruitment histories, and patterns of growth differed more between the 2 island groups than within the Palm Island group. Meekan et al. (2001) also recently found that all of the demographic traits they examined (growth, longevity, mortality, recruitment history) varied widely among several locations separated by $100 \mathrm{~s}$ of $\mathrm{km}$ in the eastern Pacific. This pattern is intuitive and perhaps not surprising. A second point is not intuitively obvious. While a large spatial scale will often reveal large differences, differences over relatively small spatial scales can also be quite pronounced. This was shown in this study by the differences in asymptotic body sizes, particularly asymptotic weight, observed between Pelorus Island and the other Palm Island group locations. However, differences were not observed on either spatial scale for some traits. Longevity was similar among all 5 locations, as were ages and sizes at maturity between the 2 island groups (Kritzer 2001). Preliminary data from the Northern Territory, Australia, suggest that size at maturity is again similar there, but longevity might be as short as 10 yr (Knuckey et al. 1996). Thus, a final point is that the spatial scale on which differences will be observed will likely vary with the variable or process being examined. This means that within a defined area of interest, some population traits can be estimated to represent the whole of the area while others will need to be estimated for distinct components of the area. The challenge for reef fish ecologists will be determining the generality of multi-scale patterns, such those described herein, in order to determine which spatial scales can be used to characterize which population traits (Choat 1998).

\section{Summary}

Some population traits of Lutjanus carponotatus showed little variation on even large spatial scales (e.g. longevity), some varied on large scales but less so on smaller scales (e.g. age structure and density), some varied on large and, to a lesser degree, small scales (e.g. growth and size structure), and others exhibited patterns that did not consistently follow gradients of scale (e.g. mortality). The diversity of these spatial patterns highlights the fact that there is no single correct scale at which to study reef fish populations, but rather that the appropriate scale will vary with the question of interest (Sale 1998). Many of the prominent ideas in coral reef fish ecology have been generated through work on small, site-attached species such as pomacentrids due to their numerical dominance and ease of collection and manipulation (Sale 1991). Work on these species has laid the foundation of our understanding of how reef fish systems are structured, and has advanced ecology in general. Now there is a need to bring less easily studied larger-bodied taxa into the fold of reef fish ecology in order to assess which of the patterns and processes identified using smaller-bodied species apply (Roberts 1996). Studies such as this can help meet this end, and therefore broaden our understanding of the dynamics of coral reef fish populations.

Acknowledgements. Thanks are due to Howard Choat, Campbell Davies, Peter Sale, Carl Walters, Tony Fowler, Stuart Ludsin, John Ackerman, Ashley Williams, an anonymous thesis examiner and 3 anonymous reviewers for constructive comments that greatly improved the quality of this manuscript. Adam Lewis and Lindsey Jones of the GIS Section of the Great Barrier Reef Marine Park Authority (GBRMPA) kindly provided the estimates of reef area at each study location. GBRMPA also provided a research grant that helped fund fieldwork. This study was conducted while the author was supported by an International Student Postgraduate Scholarship from the Commonwealth of Australia and a postgraduate stipend from the CRC Reef Research Centre. Final preparation of the manuscript took place while the author was supported by a post-doctoral fellowship through NSERCCRO grant no. 225965-00 to Peter Sale and others.

\section{LITERATURE CITED}

Aldenhoven JM (1986) Local variation in mortality rates and life-expectancy estimates of the coral-reef fish Centropyge bicolor (Pisces: Pomacanthidae). Mar Biol 92: $237-244$

Andrew NL, Mapstone BD (1987) Sampling and the description of spatial pattern in marine ecology. Oceanogr Mar Biol Annu Rev 25:39-90

Anthony KRN, Fabricius KE (2000) Shifting roles of heterotrophy and autotrophy in coral energetics under varying turbidity. J Exp Mar Biol Ecol 252:221-253

Beamish RJ (1979) Differences in the age of Pacific hake (Merluccius productus) using whole otoliths and sections of otoliths. J Fish Res Board Can 36:141-151

Caley MJ (1995) Reef-fish community structure and dynamics: an interaction between local and larger-scale processes? Mar Ecol Prog Ser 129:19-29

Cappo M, Eden P, Newman SJ, Robertson S (2000) A new approach to validation of periodicity and timing of opaque zone formation in the otoliths of eleven species of Lutjanus from the central Great Barrier Reef. Fish Bull 98:474-488

Choat JH (1998) The question of spatial scale in reef fish studies. In: Jones GP, Doherty PJ, Mapstone BM, Howlett L 
(eds) ReeFish '95: recruitment and population dynamics of coral reef fishes. CRC Reef Research Centre, Townsville, p 83-86

Craig PC, Choat JH, Axe LM, Saucerman S (1997) Population biology and harvest of the coral reef surgeonfish Acanthurus lineatus in American Samoa. Fish Bull 95:680-693

Crowder LB, Lyman SJ, Figuerina WF, Priddy J (2000) Sourcesink population dynamics and the problem of siting marine reserves. Bull Mar Sci 66:799-820

Davies CR (1995) Patterns of movement of three species of coral reef fish on the Great Barrier Reef. PhD thesis, James Cook University, Townsville

Doherty PJ (1987) The replenishment of populations of coral reef fishes, recruitment surveys, and the problems of variability manifest on multiple scales. Bull Mar Sci 41: 423-431

Doherty PJ (2002) Variable replenishment and the dynamics of reef fish populations. In: Sale PF (ed) Coral reef fishes: dynamics and diversity in a complex ecosystem. Academic Press, San Diego, p 327-355

Doherty P, Fowler A (1994) Demographic consequences of variable recruitment to coral reef fish populations: a congeneric comparison of two damselfishes. Bull Mar Sci 54: 297-313

Dudgeon CL, Gust N, Blair D (2000) No apparent genetic basis to demographic differences in scarid fishes across continental shelf of the Great Barrier Reef. Mar Biol 137: 1059-1066

Ferreira BP, Russ GR (1994) Age validation and estimation of growth rate of the coral trout, Plectropomus leopardus, (Lacepede 1802) from Lizard Island, northern Great Barrier Reef. Fish Bull 92:46-57

Forrester GE (1995) Strong density-dependent survival and recruitment regulate the abundance of a coral reef fish. Oecologia 103:275-282

Fowler AJ (1987) The development of sampling strategies for population studies of coral reef fishes. a case study. Coral Reefs 6:49-58

Gladstone W, Westoby M (1988) Growth and reproduction in Canthigaster valentini (Pisces, Tetraodontidae): a comparison of a toxic reef fish with other reef fishes. Environ Biol Fishes 21:207-221

Hart AM, Russ GR (1996) Response of herbivorous fishes to crown-of-thorns Acanthaster planci outbreaks. III. Age, growth, mortality and maturity indices of Acanthurus nigrofuscus. Mar Ecol Prog Ser 136:25-35

Higgs JB (1993) A descriptive analysis of records of the recreational reef-line fishery on the Great Barrier Reef. MSc thesis, Dept. of Marine Biology, James Cook University, Townsville

Hilomen VV (1997) Inter- and intra-habitat movement patterns and population dynamics of small reef fishes of commercial and recreational significance. PhD thesis, James Cook University, Townsville

Johnson DH (1999) The insignificance of statistical significance testing. J Wildl Manage 63:763-772

Jones GP (1991) Postrecruitment processes in the ecology of coral reef fish populations: a multifactorial perspective. In: Sale PF (ed) The ecology of fishes on coral reefs. Academic Press, San Diego, p 294-328

Kimura DK (1980) Likelihood methods for the von Bertalanffy growth curve. Fish Bull 77:765-776

Knuckey I, Hay T, Calogeras C (1996) NT coastal reef fish: population biology of the stripey (Lutjanus carponotatus). Northern Territory of Australia Primary Industries and Fisheries Fishnote 20

Kritzer JP (2001) Patterns of spatial variation in the population biology of a coral reef fish and implications for metapopulation dynamics. PhD thesis, James Cook University, Townsville

Kritzer JP, Davies CR, Mapstone BD (2001) Characterizing fish populations: effects of sample size and population structure on the precision of demographic parameter estimates. Can J Fish Aquat Sci 58:1557-1568

Levin SA (1992) The problem of pattern and scale in ecology. Ecology 73:1943-1967

Man A, Law R, Polunin NVC (1995) Role of marine reserves in recruitment to reef fisheries: a metapopulation model. Biol Conserv 71:197-204

Mapstone BD, Ayling AM (1998) An investigation of optimum methods and unit sizes for the visual estimation of abundances of some coral reef organisms. Great Barrier Reef Marine Park Authority Res Publ 47

Mapstone BD, Ayling AM, Choat JH (1998) Habitat, cross shelf and regional patterns in the distributions and abundances of some coral reef organisms on the northern Great Barrier Reef. Great Barrier Reef Marine Park Authority Res Publ 48

Meekan MG, Ackerman JL, Wellington GM (2001) Demography and age structures of coral reef damselfishes in the tropical eastern Pacific Ocean. Mar Ecol Prog Ser 212: $223-232$

Myers RA, Mertz G, Bridson J (1997) Spatial scales of interannual recruitment variations of marine, anadromous, and freshwater fish. Can J Fish Aquat Sci 54:1400-1407

Newman SJ, Williams DM (1996) Variation in reef associated assemblages of the Lutjanidae and Lethrinidae at different distances offshore in the central Great Barrier Reef. Environ Biol Fishes 46:123-138

Newman SJ, Williams DM, Russ GR (1996) Variability in the population structure of Lutjanus adetii (Castelnau, 1873) and L. quinquelineatus (Bloch, 1790) among reefs in the central Great Barrier Reef, Australia. Fish Bull 94:313-329

Newman SJ, Williams DM, Russ GR (1997) Patterns of zonation of assemblages of the Lutjanidae, Lethrinidae and Serranidae (Epinephelinae) within and among mid-shelf and outer-shelf reefs in the central Great Barrier Reef. Mar Freshw Res 48:119-128

Newman SJ, Cappo M, Williams DM (2000) Age, growth and mortality of the stripey, Lutjanus carponotatus (Richardson) and the brown-stripe snapper, L. vitta (Quoy and Gaimard) from the central Great Barrier Reef, Australia. Fish Res 48:263-275

Pitcher CR (1992) Growth of juvenile coral reef damselfish: spatial and temporal variability, and the effect of population density. Aust J Mar Freshw Res 43:1129-1149

Randall JE, Allen GR, Steene RC (1997) Fishes of the Great Barrier Reef and Coral Sea. Crawford House, Bathurst, NSW

Ricker WE (1975) Computation and interpretation of biological statistics of fish populations. Bull Fish Res Board Can 191

Roberts CM (1996) Settlement and beyond: population regulation and community structure of reef fishes. In: Polunin NVC, Roberts CM (eds) Reef fisheries. Chapman \& Hall, London, p 85-112

Robertson DR (1998) Implications of body size for interspecific interactions and assemblage organization among coralreef fishes. Aust J Ecol 23:252-257

Russ GR, Lou DC, Ferreira BP (1996) Temporal tracking of a strong cohort in the population of a coral reef fish, the coral trout, Plectropomus leopardus (Serranidae: Epinephelinae), in the central Great Barrier Reef, Australia. Can J Fish Aquat Sci 53:2745-2751 
Sale PF (1991) Introduction. In: Sale PF (ed) The ecology of fishes on coral reefs. Academic Press, San Diego, p 3-25 Sale PF (1998) Appropriate spatial scales for studies of reeffish ecology. Aust J Ecol 23:202-208

Sweka JA, Hartman KJ (2001) Effects of turbidity on prey consumption and growth in brook trout and implications for bioenergetics modelling. Can J Fish Aquat Sci 58: 386-393

Thomas CD, Kunin WE (1999) The spatial structure of populations. J Anim Ecol 68:647-657

Williams A (1997) Spatial variation in population structure of

Editorial responsibility: Otto Kinne (Editor),

Oldendorf/Luhe, Germany the red-throat emperor, Lethrinus miniatus, among regions and management zones on the Great Barrier Reef. BSc (Honours) thesis, Department of Marine Biology, James Cook University, Townsville

Williams DM (1983) Longitudinal and latitudinal variation in the structure of reef fish communities. In: Baker JT, Carter RM, Sammarco PW, Stark KP (eds) Proc Inaugural Great Barrier Reef Conf. James Cook University Press, Townsville, p 265-270

Zar JH (1984) Biostatistical analysis. Prentice-Hall, Englewood Cliffs, NJ

Submitted: December 10, 2001; Accepted: July 30, 2002

Proofs received from author(s): October 29, 2002 